\title{
Long-Term Effect of Imidapril Hydrochloride Compared With Dilazep Hydrochloride Administration on Blood Pressure and Renal Function in Patients With Chronic Glomerulonephritis
}

\author{
Hiroshi Satonaka, ${ }^{1}$ MD, Etsu Suzuki, ${ }^{1}$ MD, Hiroshi HayaKawa, ${ }^{1}$ MD, \\ Hiroaki Nishimatsu, ${ }^{1} \mathrm{MD}$, Daisuke NAGATA, ${ }^{1} \mathrm{MD}$, Shigeyoshi ObA, ${ }^{1} \mathrm{MD}$, \\ Atsuko KAMIJO, ${ }^{1} \mathrm{MD}$, Ryo TAKEDA, ${ }^{1} \mathrm{MD}$, Masao TAKAHASHI,${ }^{1} \mathrm{MD}$, \\ Yuji YAmAMOTO,${ }^{1} \mathrm{MD}$, Kenjiro KIMURA, ${ }^{1} \mathrm{MD}$, and Yasunobu HiRATA, ${ }^{1} \mathrm{MD}$
}

\section{SUMMARY}

The objective of the present study was to compare the effects of imidapril hydrochloride, an angiotensin converting enzyme inhibitor, and dilazep hydrochloride, an antiplatelet agent, on urinary protein excretion and renal function in patients with chronic glomerulonephritis.

Imidapril (2.5 or $5 \mathrm{mg} /$ day) or dilazep (300 or $450 \mathrm{mg} /$ day) was administered for 3 years. Blood pressure, proteinuria, and renal function were measured before and during the treatment. In the group administered imidapril $(n=11)$, urinary protein decreased by approximately $50 \%(2.16 \pm 1.57$ versus $0.90 \pm 0.53 \mathrm{~g} / \mathrm{g} \mathrm{Cr}, P<0.01)$ and blood pressure by $14 / 10 \mathrm{mmHg}(139.6 \pm 17.4 / 93.6 \pm 8.7 \mathrm{mmHg}$ versus $122.7 \pm 10.5 / 81.8 \pm 9.9 \mathrm{mmHg}$, $P<0.01)$ and both remained at low levels during the three years of treatment. No correlation was observed between the extent of blood pressure reduction and changes in urinary protein. Serum creatinine concentrations did not change significantly ( $1.3 \pm 0.3$ versus 1.3 $\pm 0.3 \mathrm{mg} / \mathrm{dL}, \mathrm{NS})$. In the dilazep group $(n=12)$, there were no significant changes in blood pressure, urinary protein, or serum creatinine.

These findings demonstrate that imidapril reduces proteinuria and contributes to preserve renal function, suggesting its usefulness in the treatment of patients with chronic glomerulonephritis. (Int Heart J 2005; 46: 701-710)

Key words: IgA nephropathy, ACE inhibitor, Antiplatelet agent

IN Japan, there are more than two hundred thousand patients with end stage renal disease (ESRD) undergoing maintenance hemodialysis. Diabetic nephropathy and chronic glomerulonephritis (CGN) are the leading causes of the ESRD. Among CGN patients, immunoglobulin A (IgA) nephropathy is regarded as the

From the ${ }^{1}$ Department of Internal Medicine, Graduate School of Medicine, University of Tokyo, Tokyo, Japan.

Address for correspondence: Yasunobu Hirata, MD, Department of Cardiovascular Medicine, University of Tokyo, 7-3-1

Hongo, Bunkyo-ku, Tokyo 113-8655, Japan.

Received for publication February 7, 2005

Revised and accepted March 24, 2005. 
etiology in at least fifty percent of the cases. ${ }^{1)}$ The efficacy of angiotensin converting enzyme (ACE) inhibitors in the treatment of these diseases has recently been demonstrated ${ }^{2-4)}$ In Japan, although the administration of ACE inhibitors for the treatment of chronic renal diseases has become increasingly common, there still exist regional discrepancies in the frequency of their actual use, and this fact might be one of the reasons for the regional differences in the incidence of ESRD. ${ }^{5)}$

Imidapril hydrochloride is a long-acting ACE inhibitor with no sulfhydryl group whose renoprotective effects, including reduction of proteinuria, have been demonstrated in Dahl rats ${ }^{6}$ and in rats given NOS inhibitors. ${ }^{7)}$ Furthermore, in clinical trials conducted in Japan, imidapril has been shown to significantly decrease microalbuminuria in patients with insulin dependent diabetes mellitus. ${ }^{8)}$ The clinical efficacy of imidapril in CGN patients, however, has not been fully evaluated. Moreover, ACE inhibitor treatment is not considered to be an appropriate therapy for CGN in Japan and as such is not covered by the national health insurance program. On the other hand, antiplatelet agents have been used in the treatment of renal diseases for many years since long before the advent of ACE inhibitors. Among the antiplatelet agents available, dilazep hydrochloride has been reported to reduce proteinuria in $\operatorname{IgA}$ and diabetic nephropathies.9-11) According to these reports, dilazep was approved for administration to proteinuric patients, including those with IgA nephropathy in Japan. In this study, the effects of imidapril and dilazep on proteinuria, renal function, and blood pressure in CGN patients were compared.

\section{METHODS}

CGN patients with overt proteinuria excretion accompanied by serum creatinine $(\mathrm{Cr})$ concentrations under $2 \mathrm{mg} / \mathrm{dL}$ were enrolled in the study $(n=23,18$ men and 5 women, 23 - 66 years old). Diagnosis was established based on renal biopsy findings or general laboratory data. In 19 out of the 23 patients, the diagnosis was confirmed by histopathological examination of renal biopsy specimens. In the remaining 4 patients, renal biopsy was not performed either because of old age (over 50 years) or an elevated serum creatinine level (over $1.5 \mathrm{mg} / \mathrm{dL}$ ). All patients had proteinuria greater than $0.5 \mathrm{~g} / \mathrm{g} \mathrm{Cr}$, and none had any other diseases such as marked hypertension, diabetes, collagen diseases, or infectious diseases that could account for the proteinuria. The patients were divided into an imidapril group $(n=11)$ and a dilazep $(n=12)$ group according to their baseline blood pressure because imidapril administration was approved for only hypertensive patients. 
Imidapril was started at an oral dose of $2.5 \mathrm{mg}$ once a day and increased to $5 \mathrm{mg}$, as required. Dilazep was administered orally at a daily dose of 300 or 450 $\mathrm{mg}$ divided into three equal doses of 100 or $150 \mathrm{mg}$. Both groups were treated with the corresponding drug for 36 months. The patients were allowed to take their usual medications without any changes during the study period.

Blood pressure, serum creatinine, blood urea nitrogen, total protein, albumin, and total cholesterol levels were measured at the start of the administration and every 6 months thereafter during the study period. Urine was collected for 24 hours prior to each examination, a portion of which was used for the measurement of urinary protein and creatinine concentration. These parameters were measured with an automated analyzer. Blood pressure was measured using a mercury sphygmomanometer with the patient in the sitting position.

This open-label study was conducted in accordance with the principles of the Declaration of Helsinki. All participants provided informed consent after receiving a detailed explanation of the study.

Statistical analyses: All data are expressed as the mean value \pm SD. Statistical comparisons were made by analysis of variance followed by the Student-Neumann-Keuls test. Evaluation of correlation was determined by the least square method. A value of $P<0.05$ was considered statistically significant.

\section{Results}

Patient characteristics: The pretrial characteristics of the two groups are shown in Table I. With respect to the etiology of CGN, 7 patients in the imidapril group

Table I. Clinical Background of Patients With Proteinuria Administered Imidapril or Dilazep

\begin{tabular}{lcc}
\hline & Imidapril & Dilazep \\
\hline $\mathrm{N}$ & 11 & 12 \\
Age (years) & $42.5 \pm 11.4$ & $35.7 \pm 11.5$ \\
Body weight (kg) & $66.0 \pm 12.5$ & $63.5 \pm 4.4$ \\
Sex (M:F) & $9: 2$ & $9: 3$ \\
Diagnosis & 7 & \\
IgA nephropathy & 0 & 8 \\
Minimal change & 0 & 1 \\
Non-IgA mesangial proliferative & & 1 \\
$\quad$ glomerulonephritis & 0 & 1 \\
Focal glomerular sclerosis & 0 & 1 \\
Membranous nephropathy & 1 & 0 \\
Membranoproliferative glomerulonephritis & & \\
Other medication & 2 & 1 \\
Allopurinol & & \\
\hline
\end{tabular}

Values are the mean \pm SD. 
Table II. Baseline Blood Pressure and Laboratory Data of Patients With Proteinuria Administered Imidapril or Dilazep

\begin{tabular}{lcc}
\hline & Imidapril & Dilazep \\
\hline $\mathrm{N}$ & 11 & 12 \\
Systolic blood pressure (mmHg) & $139.6 \pm 17.4$ & $118.2 \pm 13.0^{*}$ \\
Diastolic blood pressure (mmHg) & $93.6 \pm 8.7$ & $67.0 \pm 9.4^{*}$ \\
Proteinuria (g/g Cr) & $2.16 \pm 1.57$ & $1.15 \pm 0.99$ \\
Total protein $(\mathrm{g} / \mathrm{dL})$ & $6.6 \pm 0.5$ & $7.2 \pm 0.5$ \\
Albumin $(\mathrm{g} / \mathrm{dL})$ & $3.8 \pm 0.5$ & $4.3 \pm 0.4$ \\
Total cholesterol (mg/dL) & $219 \pm 67$ & $210 \pm 32$ \\
Blood urea nitrogen $(\mathrm{mg} / \mathrm{dL})$ & $18.8 \pm 3.9$ & $14.8 \pm 3.5^{*}$ \\
Creatinine $(\mathrm{mg} / \mathrm{dL})$ & $1.3 \pm 0.3$ & $1.1 \pm 0.3$ \\
Potassium $(\mathrm{mEq} / \mathrm{L})$ & $4.5 \pm 0.6$ & $4.2 \pm 0.3$ \\
\hline
\end{tabular}

Values are the mean \pm SD. * indicates $P<0.05$ versus imidapril group.

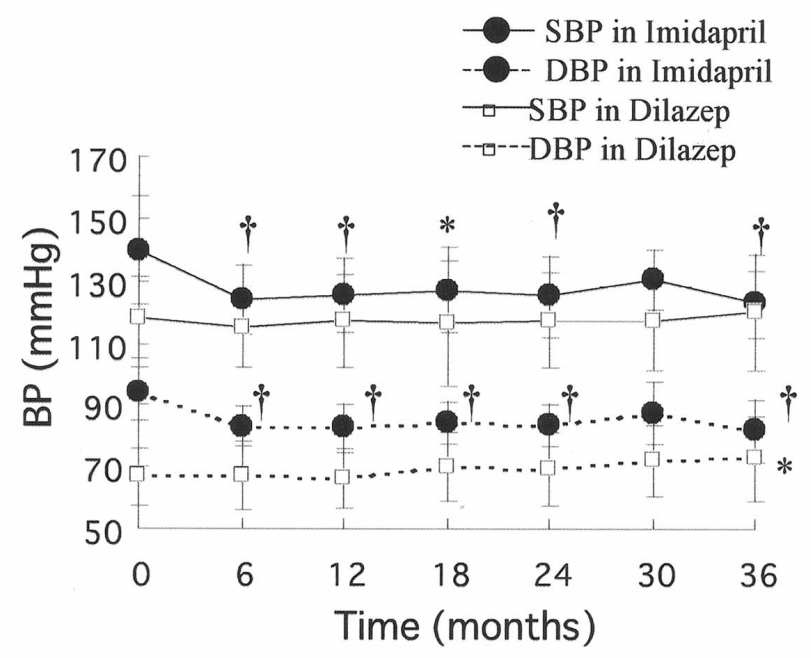

Figure 1. Time course changes in blood pressure in patients with proteinuria administered imidapril or dilazep. Values are the mean \pm SD. * indicates $P<0.05$. $\dagger P<0.01$ versus time 0 .

and 8 in the dilazep group had $\operatorname{IgA}$ nephropathy. There were no significant differences in any of the other characteristics, such as body weight or concomitant medications, between the two groups. However, both SBP and DBP were significantly higher in the imidapril group (Table II).

The imidapril group had slightly more proteinuria, although a statistically significant difference was not found between the two groups. There was no sig- 
nificant difference in serum creatinine concentration, while the serum BUN level was significantly higher in the imidapril group (Table II).

The average dose of imidapril administered at 36 months was $4.0 \pm 1.3 \mathrm{mg} /$ day and that of dilazep $325.0 \pm 58.4 \mathrm{mg} /$ day.

Effects on blood pressure reduction (Figure 1): In the imidapril group, the average SBP and DBP at baseline were $139.6 \pm 17.4 \mathrm{mmHg}$ and $93.6 \pm 8.7 \mathrm{mmHg}$, respectively. Significant reductions in SBP and DBP started to be observed at six months; they stabilized at $123.6 \pm 11.0 \mathrm{mmHg}$ and $83.1 \pm 6.3 \mathrm{mmHg}$ during the study period and were $122.7 \pm 10.5 \mathrm{mmHg}$ and $81.8 \pm 9.9 \mathrm{mmHg}$, respectively, at the end of the study.

In the dilazep group, there was no significant change in SBP $(120.0 \pm 18.6$ $\mathrm{mmHg}$ at 36 months). DBP increased gradually to $72.8 \pm 13.5 \mathrm{mmHg}$ at 36 months. Although the difference was significant in comparison to the prestudy level, it remained within the normal range.

Changes in urinary protein excretion: The reductions in urinary protein excretion adjusted by urinary creatinine are shown in Figure 2. In the imidapril group, a significant reduction by about $1 \mathrm{~g} / \mathrm{g} \mathrm{Cr}$ was found in the second month of treat-

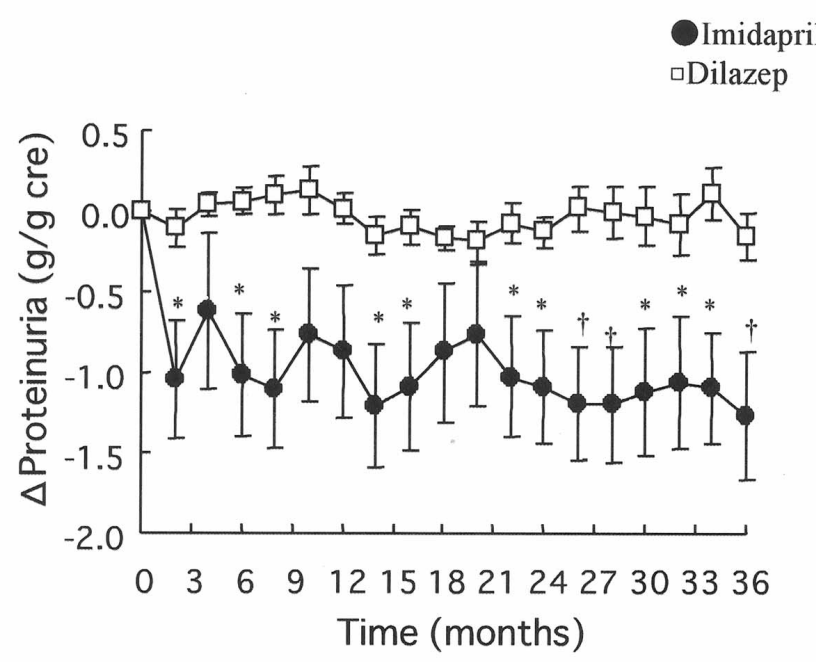

Figure 2. Time course changes in urinary protein excretion in patients treated with imidapril or dilazep. Values are the mean $\pm \mathrm{SD}$. * indicates $\mathrm{P}<0.05$. $\dagger P<0.01$ versus time 0 . 

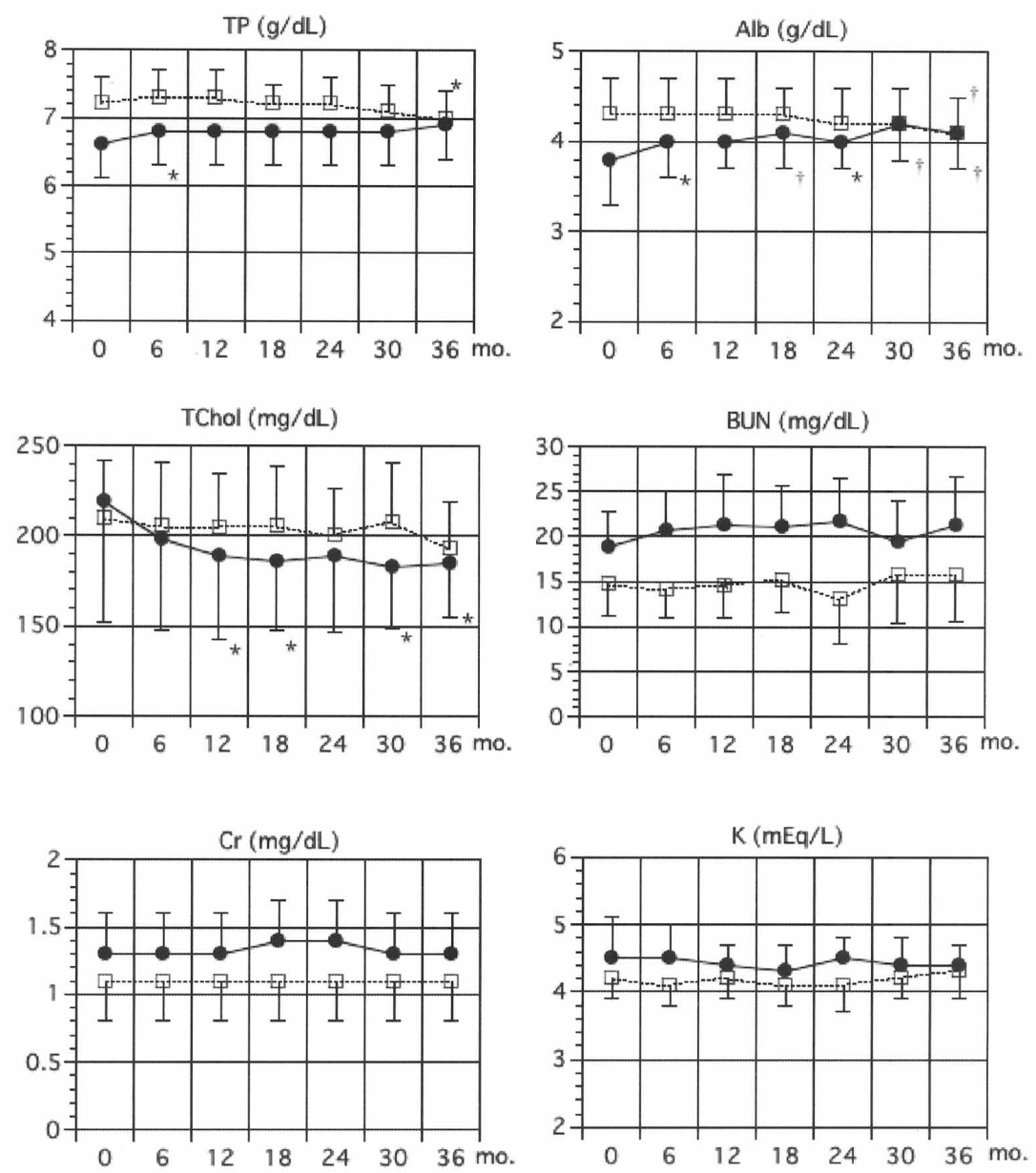

\section{imidapril $\quad-.--$ dilazep}

Figure 3. Time course changes in serum concentrations of biochemical markers in patients with proteinuria administered imidapril or dilazep. Values are the mean \pm SD. * indicates $P<0.05$. $† P<0.01$ versus time 0 .

ment; at 6 months and later, when blood pressure had already stabilized, urinary protein excretion continued to decrease gradually. Proteinuria decreased from the prestudy level of $2.16 \pm 1.57 \mathrm{~g} / \mathrm{g} \mathrm{Cr}$ to $0.90 \pm 0.53 \mathrm{~g} / \mathrm{g} \mathrm{Cr}$ at 36 months. In the dilazep group, urinary protein decreased from $1.15 \pm 0.99 \mathrm{~g} / \mathrm{g} \mathrm{Cr}$ at the start of administration to $1.00 \pm 0.81 \mathrm{~g} / \mathrm{g} \mathrm{Cr}$ at 36 months. 
The coefficient of correlation between the decrease in blood pressure and that of proteinuria was determined in the imidapril group from their rates of change at 6 and 36 months. There was no correlation at these time points between the rate of reduction in proteinuria and that of SBP or DBP $(\% \Delta$ proteinuria versus \% $\triangle \mathrm{SBP}: \mathrm{r}=0.429, P=\mathrm{NS}$ at 6 months; $\mathrm{r}=0.050, P=\mathrm{NS}$ at 36 months), suggesting that the proteinuria-reducing effects of imidapril did not depend on a reduction of blood pressure.

Effects on renal function: In the imidapril group, serum creatinine and BUN concentrations were $1.27 \pm 0.30 \mathrm{mg} / \mathrm{dL}$ and $18.8 \pm 3.9 \mathrm{mg} / \mathrm{dL}$ at the start of administration and $1.34 \pm 0.30 \mathrm{mg} / \mathrm{dL}$ and $21.3 \pm 5.5 \mathrm{mg} / \mathrm{dL}$ at 36 months, respectively. There was no significant change in either parameter. No significant change in serum creatinine or BUN was observed in the dilazep group either. As shown in Figure 3, while the serum protein and albumin concentrations gradually increased in the imidapril group, there were no changes in the dilazep group. A marked reduction in total cholesterol concentration was also seen in the imidapril group, but not in the dilazep group.

Side effects and other abnormal laboratory data: No side effects or other abnormal laboratory data were observed in either group. It should be noted that no adverse effects such as acute deterioration of renal function, hyperkalemia, symptoms associated with hypotension, or dry cough were observed as a consequence of the imidapril administration.

\section{DISCUSSION}

In the present study, imidapril was administered for 36 months to patients with overt proteinuria and hypertension, and its effects on proteinuria were investigated. The results demonstrated that in the imidapril group blood pressure stabilized at a lower level and that proteinuria decreased continuously during treatment. Since no correlation was found between the degree of reduction in proteinuria and blood pressure, this proteinuria-reducing effect seemed to be independent of the extent of blood pressure reduction. ACE inhibitors owe much of their proteinuria-reducing action to their effects on glomerular hemodynamics, dilating efferent arterioles greater than afferent arterioles, and thus lowering intraglomerular pressure. ${ }^{12)}$ It is also reported that ACE inhibitors improve glomerular basement membrane charge and size barriers, as well as endothelial function of the renal vasculature, and inhibit cellular proliferation and extracellular matrix production in the mesangium. Such actions may contribute to the decrease of proteinuria observed during the long-term administration of imidapril. The results of the present study suggest that imidapril can be used for long periods in hypertensives with overt proteinuria and that it probably exerts renoprotective 
effects. In this regard, our findings are compatible with the results of past largescale clinical trials involving patients with renal dysfunction, especially with diabetic nephropathy. ${ }^{2,3)}$

Recently, the fact that proteinuria itself exerts deleterious effects on the progression of renal dysfunction has become a focus of much attention. It is well recognized that in patients with severe proteinuria, renal function deteriorates rapidly. ${ }^{13,14)}$ On the other hand, it has also been reported that by decreasing proteinuria the process of glomerular filtration rate (GFR) reduction can be retarded. It has been demonstrated that mechanical and biochemical stress are inflicted on renal tissue when serum-originated protein is filtrated in the glomeruli and reabsorbed along the proximal tubules. ${ }^{15,16)}$ Proteinuria is, accordingly, not only an index of pathogenic activity in the glomeruli, but it also contributes directly to the progression of renal dysfunction. Therefore, it is important to reduce the level of proteinuria as much as possible. Imidapril reduced proteinuria by $1 \mathrm{~g} / \mathrm{g} \mathrm{Cr}$ in CGN patients. It has been shown that for each gram of proteinuria reduced per day the GFR decline was slowed by about 1.0 to $2.0 \mathrm{~mL} / \mathrm{min}$ per year. ${ }^{17,18)} \mathrm{How}-$ ever, we observed no difference in renal function during the three years of treatment with imidapril compared with the dilazep group, whose proteinuria was not reduced by the drug. The reason for this lack of difference in renal function is not clear, however, a longer follow-up period will presumably make a difference considering that patients in the dilazep group had relatively good baseline renal function. The fact that patients in the dilazep group had an obviously lower baseline blood pressure, and consequently were likely to have better renal function and less proteinuria, may also have been one of the confounding factors.

It has been reported that dilazep significantly reduces urinary protein or albumin excretion in patients with IgA nephropathy, ${ }^{9)}$ early-stage diabetic nephropathy ${ }^{10,11)}$ and normotensive autosomal dominant polycystic kidney disease. ${ }^{19)}$ Yoshida, et $a l^{20)}$ analyzed the relation between a reduction in proteinuria and renal histological findings in 46 patients with IgA nephropathy administered dilazep. In 18 patients whose proteinuria was reduced by more than $25 \%$, the degrees of glomerular sclerosis, crescent formation, mesangial matrix, and tubulo-interstitial lesions were milder compared with those who had a persistently high proteinuria. IgA or IgG depositions in the glomeruli were also milder in the group responsive to the treatment. In the present study, proteinuria decreased by more than $25 \%$ in about $15 \%$ of the patients in the dilazep group. There might have been a relatively large number of patients in this group whose renal histopathological status was more advanced than could be estimated from their blood pressure, serum creatinine concentration, and proteinuria. Furthermore, it has been shown that dilazep decreases the release of lipopolysaccharide from cul- 
tured mesangial cells and inhibits their proliferation. ${ }^{21)}$ This effect may have prevented renal function deterioration even without reductions in proteinuria.

Imidapril decreased proteinuria by half, while this effect was not observed with dilazep. Although it is sometimes difficult to evaluate proteinuria in outpatients, the degree of reduction achieved by imidapril was substantial and not simply due to errors associated with urine storage or measurements. In fact, significant increases in serum total protein and albumin concentrations support this point. The marked serum total cholesterol reduction obtained only in the imidapril group without the use of cholesterol-lowering drugs is presumably an effect mediated by a reduction in proteinuria.

Conclusions: In summary, imidapril reduced proteinuria during three years of treatment and was useful for the maintenance of renal function. Dilazep also helped to maintain renal function without reducing proteinuria. Further studies conducted on larger numbers of patients for longer durations will be required in the future.

\section{ACKNOWLEDGMENTS}

This study was supported by Grant-in-Aid \#13557061 from the Ministry of Education, Culture, Sports, Science and Technology of Japan. We thank Ms Etsuko Taira, Ms Marie Morita, and Ms Reiko Sato for their technical assistance.

\section{REFERENCES}

1. Japanese Society for Dialysis Therapy. An overview of regular dialysis treatment in Japan (as of Dec. 31, 2002). J Jpn Soc Dial Ther 2004; 37: 1-24. (Japanese)

2. Lewis EJ, Hunsicker LG, Bain RP, Rohde RD. The effect of angiotensin-converting-enzyme inhibition on diabetic nephropathy. The Collaborative Study Group. N Engl J Med 1993; 329: 1456-62.

3. Maschio G, Alberti D, Janin G, et al. Effect of the angiotensin-converting-enzyme inhibitor benazepril on the progression of chronic renal insufficiency. The Angiotensin-Converting-Enzyme Inhibition in Progressive Renal Insufficiency Study Group. N Engl J Med 1996; 334: 939-45.

4. The GISEN Group (Gruppo Italiano di Studi Epidemiologici in Nefrologia): Randomised placebo-controlled trial of effect of ramipril on decline in glomerular filtration rate and risk of terminal renal failure in proteinuric, non-diabetic nephropathy. Lancet 1997; 349: 1857-63.

5. Usami T, Nakao N, Fukuda M, et al. Maps of end-stage renal disease and amounts of angiotensin-converting enzyme inhibitors prescribed in Japan. Kidney Int 2003; 64: 1445-9.

6. Yoneda H, Toriumi W, Ohmachi Y, Okumura F, Fujimura H, Nishiyama S. Involvement of angiotensin II in development of spontaneous nephrosis in Dahl salt-sensitive rats. Eur J Pharmacol 1998; 362: 213-9.

7. Kashiwagi M, Shinozaki M, Hirakata $\mathrm{H}$, et al. Locally activated renin-angiotensin system associated with TGF-s1 as a major factor for renal injury induced by chronic inhibition of nitric oxide synthase in rats. J Am Soc Nephrol 2000; 11: 616-24.

8. Katayama S, Kikkawa R, Isogai S, et al. Effect of captopril or imidapril on the progression of diabetic nephropathy in Japanese with type 1 diabetes mellitus: a randomized controlled study (JAPAN-IDDM). Diabetes Res Clin Pract 2002; 55: 113-21. 
9. Inage H, Koyama A, Narita M, Tojo S. Effects of the antiplatelet agents, dipyridamole and dilazep dihydrochloride, on in vivo platelet function and proteinuria. Jpn J Nephrol 1985; 27: 1261-70.

10. Koide H, Totsuka Y, Sugisaki T, et al. Clinical effect of the anti-platelet drug, dilazep dihydrochloride, in patients at the microalbuminuric stage of diabetic nephropathy--a multi-center study. Jpn J Nephrol 1995; 37 : 644-8.

11. Nakamura T, Ushiyama C, Shimada N, et al. Effect of the antiplatelet drug dilazep dihydrochloride on urinary podocytes in patients in the early stage of diabetic nephropathy. Diabetes Care 2000; 23: 1168-71.

12. Brenner BM, Lawler EV, Mackenzie HS. The hyperfiltration theory. a paradigm shift in nephrology. Kidney Int 1996; 49: 1774-7. (Review)

13. Keane WF. Proteinuria: its clinical importance and role in progressive renal disease. Am J Kidney Dis 2000; 35: S97-105. (Review)

14. Ruggenenti P, Perna A, Mosconi L, et al. Proteinuria predicts end-stage renal failure in non-diabetic chronic nephropathies. The "Gruppo Italiano di Studi Epidemiologici in Nefrologia" (GISEN). Kidney Int Suppl 1997; 63: S54-7.

15. Hebert LA, Wilmer WA, Falkenhain ME, Ladson-Wofford SE, Nahman NS Jr, Rovin BH. Renoprotection: one or many therapies? Kidney Int 2001; 59: 1211-26. (Review)

16. Zoja C, Morigi M, Remuzzi G Proteinuria and phenotypic change of proximal tubular cells. J Am Soc Nephrol 2003; 14 (Suppl 1): S36-41.

17. Ruggenenti P, Perna A, Remuzzi G. GISEN Group Investigators. Retarding progression of chronic renal disease: the neglected issue of residual proteinuria. Kidney Int 2003; 63: 2254-61.

18. Peterson JC, Adler S, Burkart JM, et al. Blood pressure control, proteinuria, and the progression of renal disease. The Modification of Diet in Renal Disease Study. Ann Intern Med 1995; 123: 754-62.

19. Nakamura T, Ushiyama C, Takahashi Y, et al. Effect of dilazep dihydrochloride on urinary albumin excretion in patients with autosomal dominant polycystic kidney disease. Nephron 2001; 88: 80-2.

20. Yoshida H, Kanatsu K, Muso E, et al. Effects of an anti-platelet drug (dilazep) in IgA nephropathy: comparison of clinical effects with renal biopsy findings. Jpn J Nephrol 1994; 36: 339-44.

21. Gohda T, Makita Y, Shike T, Funabiki K, Shirato I, Tomino Y. Dilazep hydrochloride, an antiplatelet drug, inhibits lipopolysaccharide-induced mouse mesangial cell IL-6 secretion and proliferation. Kidney Blood Press Res 2001; 24: 33-8. 